\title{
Effects of Labeling Patients as Prehypertensive
}

\author{
Anthony J. Viera, MD, MPH, Kara Lingley, BSPH, and Denise Esserman, PhD
}

Background: Labeling patients as hypertensive has some negative effects. The effects of being labeled as having prehypertension are unknown. We examined whether the label of prehypertension exerts a negative effect on patients' perceived health and whether it motivates people to adopt lifestyle recommendations to prevent hypertension.

Methods: We randomized 97 prehypertensive adults to either a labeling message or a generic (no label) message. At 3 months we assessed self-reports of change in perceived health and reported adoption of lifestyle recommendations to try to prevent hypertension.

Results: Except for more participants with asthma in the label group, the 2 groups were similar at baseline. Among the 70 participants who provided 3-month follow-up data, 18 people $(56 \%)$ in the nolabel group and 22 people $(58 \%)$ in the label group reported their health as the same; 13 people (41\%) in the no label group and 16 people (42\%) in the label group reported health as better; and 1 person (in no label group) reported his health as worse. At 3 months there were no differences in reports of changing eating habits (risk ratio [RR], 1.06; 95\% CI, 0.86-1.31), cutting down on salt (RR, 0.99; 95\% CI, 0.84-1.15), reducing alcohol intake (RR, 1.23; 95\% CI, 0.80-1.90), or exercising (RR, 1.17; 95\% CI, 0.91-1.51) to try to prevent hypertension.

Conclusion: Being labeled as prehypertensive seems to exert neither harmful nor helpful effects. (J Am Board Fam Med 2010;23:571-583.)

Keywords: Hypertension, Diagnosis, Health Status

Although the benefits of diagnosing and treating hypertension outweigh the risks of leaving hypertensive patients untreated, a stream of evidence has shown that being diagnosed as hypertensive has some negative effects. For example, a landmark study published in 1978 demonstrated that patients who were diagnosed with hypertension had an $80 \%$ increase in absenteeism from work in the 2 years after the diagnosis. ${ }^{1}$ This increase was attributed to

This article was externally peer reviewed.

Submitted 1 March 2010; revised 14 April 2010; accepted 20 April 2010.

From the Department of Family Medicine (AJV, KL), the Department of Medicine (DE), and the Department of Biostatistics (DE), University of North Carolina at Chapel Hill, Chapel Hill.

Funding: This study was funded by the American Academy of Family Physicians/American Academy of Family Physicians Foundation Joint Grant Awards Program (grant no. JGAP G0707AP) and the National Institutes of Health (grant nos. KL2RR025746; K12RR17667; and UL1 RR025747).

Prior presentation: Presented as an abstract for the 2010 Clinical and Translational Research and Education Meeting, Washington, DC, April 5-7, 2010.

Conflict of interest: none declared.

Corresponding author: Anthony J. Viera, MD, MPH, Department of Family Medicine, University of North Carolina at Chapel Hill, 590 Manning Drive, CB 7595, Chapel Hill, NC 27599 (E-mail: Anthony_viera@med.unc.edu). being "labeled" with a diagnosis of hypertension and was not related to antihypertensive treatment or degree of blood pressure (BP) control. ${ }^{1}$ Other studies showed similar negative effects. ${ }^{2,3}$ The effects of being labeled as hypertensive are reported to last for a number of years. ${ }^{4}$ Other important negative effects of being labeled as hypertensive include an increase in psychological discomfort, marital discord, and depressive symptoms. ${ }^{5,6}$ In more recent studies, patients who were labeled as hypertensive demonstrated lower self-rated health and health-related quality of life. ${ }^{7,8}$ Being labeled as having hypertension may even affect patients' perceptions of how long it will take them to recover from unrelated acute illnesses.

In 2003, the Seventh Report of the Joint $\mathrm{Na}$ tional Committee (JNC) on Prevention, Detection, Evaluation, and Treatment of High Blood Pressure (the JNC 7 report) introduced the term "prehypertension." ${ }^{10}$ According to the JNC 7 report, people with systolic BP between 120 to $139 \mathrm{~mm} \mathrm{Hg}$ or diastolic BP between 80 to $89 \mathrm{~mm} \mathrm{Hg}$, with neither in the hypertensive range $(\geq 140 / 90 \mathrm{~mm} \mathrm{Hg})$, are said to have prehypertension. It is estimated that $31 \%$ of American adults have prehypertension (in addition to the $27 \%$ that have hypertension). ${ }^{11} \mathrm{Be}$ - 
cause cardiovascular risk doubles with each increment of 20/10 $\mathrm{mm} \mathrm{Hg}$ above 115/75 $\mathrm{mm} \mathrm{Hg}$ and progresses to hypertension at a rate of $19 \%$ over 4 years, it is recommended that patients with prehypertension be counseled to adopt lifestyle modifications to lower their BP in an effort to prevent or delay hypertension. ${ }^{10,12}$

Although the effects on patients of being labeled as hypertensive are well established, the effects of labeling patients as prehypertensive are unknown. This label might encourage patients to adopt recommended lifestyle modifications, which would be a positive effect. On the other hand, it is possible that a being labeled prehypertensive will affect patients negatively, causing them to have lower selfreported health or adopt the "sick role." Finally, it is conceivable that such a label would have minimal or no effect. In this study we sought to examine whether diagnosing and informing patients about prehypertension (labeling) is associated with a change in health symptoms or adoption of lifestyle modifications recommended for preventing hypertension.

\section{Methods}

\section{Setting and Recruitment}

This study took place in a stand-alone family medicine center affiliated with a public university. The center provides comprehensive primary care to a wide variety of patients. More than 200 patients are seen daily (43,254 visits in 2005 to 2006); $65 \%$ are women. Approximately 29\% are African American and $2 \%$ are Hispanic. Twelve percent receive Medicaid and 23\% receive Medicare. Benign essential hypertension is the most frequently coded diagnosis during patient visits.

Patients were recruited via signs announcing a "Preventing High Blood Pressure Study." Signs were posted in examination rooms and at vital sign stations. Patients were eligible if they (1) were at least 24 years of age, (2) had recently had a BP measurement at the center that was 120 to $139 \mathrm{~mm}$ $\mathrm{Hg}$ systolic or between 80 to $89 \mathrm{~mm} \mathrm{Hg}$ diastolic with neither $\geq 140 / 90 \mathrm{~mm} \mathrm{Hg}$, (3) spoke and read English, and (4) were able to be contacted by telephone. Exclusion criteria were (1) diagnosis of hypertension or use of antihypertensive medications, (2) diagnosis of diabetes or chronic kidney disease, or (3) pregnancy.

Interested patients contacted the study coordinator (KL), who confirmed preliminary eligibility and scheduled the patient for a study visit. During this visit informed consent was obtained and the previous visit's recorded BP was confirmed, via electronic record review, to be in the prehypertension range. Patients whose most recent $\mathrm{BP}$ was not in the prehypertensive range were ineligible to continue. After a 10- to 15 -minute period of sitting, the $\mathrm{BP}$ of the participant was obtained using a validated oscillometric office BP monitor (Vital Signs, Welch Allyn, Inc., Skaneateles, NY) using recommended positioning and a cuff appropriate for upper-arm circumference. Thirty to 60 seconds later the measurement was repeated on the same arm (this is a technique that has been shown to avoid venous congestion while minimizing variability). ${ }^{13}$ The 2 measurements were averaged to yield a single BP reading for the visit. Participants whose mean BP from these measurements was not in the prehypertensive range were ineligible to continue. This study was approved by the Office of Human Subjects Research of the University of North Carolina at Chapel Hill.

\section{Baseline Data and Randomization}

Participants who were confirmed to have prehypertension based on 2 readings ${ }^{10,12}$ (the previous office visit and the initial study visit) completed a baseline self-administered questionnaire containing demographic items, medical history questions (including history of known prehypertension), and a standard self-reported health question from the 36-item Short Form (SF-36) questionnaire. ${ }^{14} \mathrm{We}$ chose to include the SF-36 self-reported health question because of its simplicity and the fact that it is widely known and valid across a wide variety of populations. The questionnaire's overall Flesch Kincaid reading level was grade 4.4. Participants were then randomized in permuted blocks (sizes 4, 4, and 6) to a "label" or "no label" group. To conceal allocation, we used sequentially numbered, opaque, sealed envelopes of equal size and weight, lined on the inside with aluminum foil.

\section{Intervention}

Those in the "label" group received a standardized message delivered by a trained research assistant. The scripted message (Appendix 1) was adapted from materials on the National Heart, Lung, and Blood Institute website ${ }^{15}$ designed to teach people about lifestyle modifications to lower high BP. The participant was told that he/she had prehyperten- 
sion; that was followed by a description of various lifestyle recommendations. Within the message the term "prehypertension" was mentioned several times. Those in the "no label" group received a very similar standardized message (Appendix 2) about lifestyle modifications without any mention of prehypertension. Printed summaries of the messages were provided to participants in both groups. Participants were given a $\$ 20$ cash incentive for completing the baseline visit.

\section{Follow-up Assessments}

Three months after the baseline visit, participants were sent a brief written questionnaire (reading level, grade 5.7) with a pre-addressed, stamped return envelope and a $\$ 5$ cash incentive. One question asked, Compared with 3 months ago, how would you rate your health in general now? Response choices were: "much better now than 3 months ago," "somewhat better now than 3 months ago," "about the same as 3 months ago," "somewhat worse than 3 months ago," or "much worse now than 3 months ago." We also again included the self-reported health status question from the SF-36, as well as questions from module 5 of the 2005 Behavior Risk factor Surveillance System, which was adapted to reflect actions being taken to "prevent" high BP rather than actions being taken to "lower or control" high BP. ${ }^{16}$ Participants whose follow-up questionnaires were not received within 2 weeks were contacted by phone and offered the opportunity to provide answers at that time.

\section{Sample Size Calculation}

Our aim was to have at least 30 patients in each group complete the 3-month follow-up questionnaire. We derived this sample size using the following question as the primary outcome: Compared with 3 months ago, how would you rate your health in general now? We believed that there would be a large proportion of respondents who would report no change in health status during the 3 -month follow-up period ( $70 \%$ to 90\%) and we hypothesized that there would be a larger proportion of respondents in the label group who reported worse health compared with those in the no label group. Using the sample size methods proposed by Zhao et $\mathrm{al}^{17}$ for the Wilcoxon-MannWhitney test adjusting for ties, we developed 3 scenarios in which we would achieve $80 \%$ power for $\alpha=$ 0.05 and approximately 30 patients per group (Appendix 3). In the first scenario, $10 \%$ of the label group had "much worse" health compared with $0 \%$ of the no label group. We calculated power to be approximately the same for the scenarios even if the data were collapsed into a 3-point Likert scale (worse, the same, better). For example, in the second scenario, $25 \%$ of the label group would report "much worse" or "somewhat worse" compared with $5 \%$ of the no label group. In the third scenario, $20 \%$ of the label group would report worse health compared with $0 \%$ in the no label group.

\section{Analysis}

Baseline characteristics of the groups were compared using the $\chi^{2}$ test of association (or Fisher's exact test, when appropriate) or $t$ test. For our primary outcome of health status at 3 months compared with baseline, ordinal responses of "much better now than 3 months ago" and "somewhat better now than 3 months ago" were combined as an outcome of "better." Similarly, responses of "somewhat worse than 3 months ago" and "much worse now than 3 months ago" were combined as an outcome of "worse." We compared the distribution of the outcome for the label and no label groups using the Wilcoxon-Mann-Whitney test. ${ }^{18,19} \mathrm{We}$ also examined for a shift in the median of the distribution in overall self-reported health status at 3-month follow-up using the Wilcoxon-MannWhitney test. Finally, we estimated the proportions of respondents taking each action to prevent high $\mathrm{BP}$ in the label and no label groups and reported difference in these proportions using risk ratios with $95 \%$ CIs. Participants were analyzed in the group to which they were randomized.

\section{Results \\ Study Participants}

During the 2 years of this project, 142 people contacted the study coordinator and expressed interest in participating; 100 of these 142 were randomized to either the label group or no label group (Figure 1). Three people indicated at baseline that they previously had been told by a health care professional that they had "prehypertension" and were therefore excluded from analysis. Except for a higher proportion of asthma in the label group, the 2 groups were similar in terms of demographics and medical history (Table 1$)$. The mean $( \pm$ SD) age of participants was $41( \pm 11)$ years (range, 24-67 years). Our 3-month follow-up response rate was 
Figure 1. Participant flow-through study. BP, blood pressure.

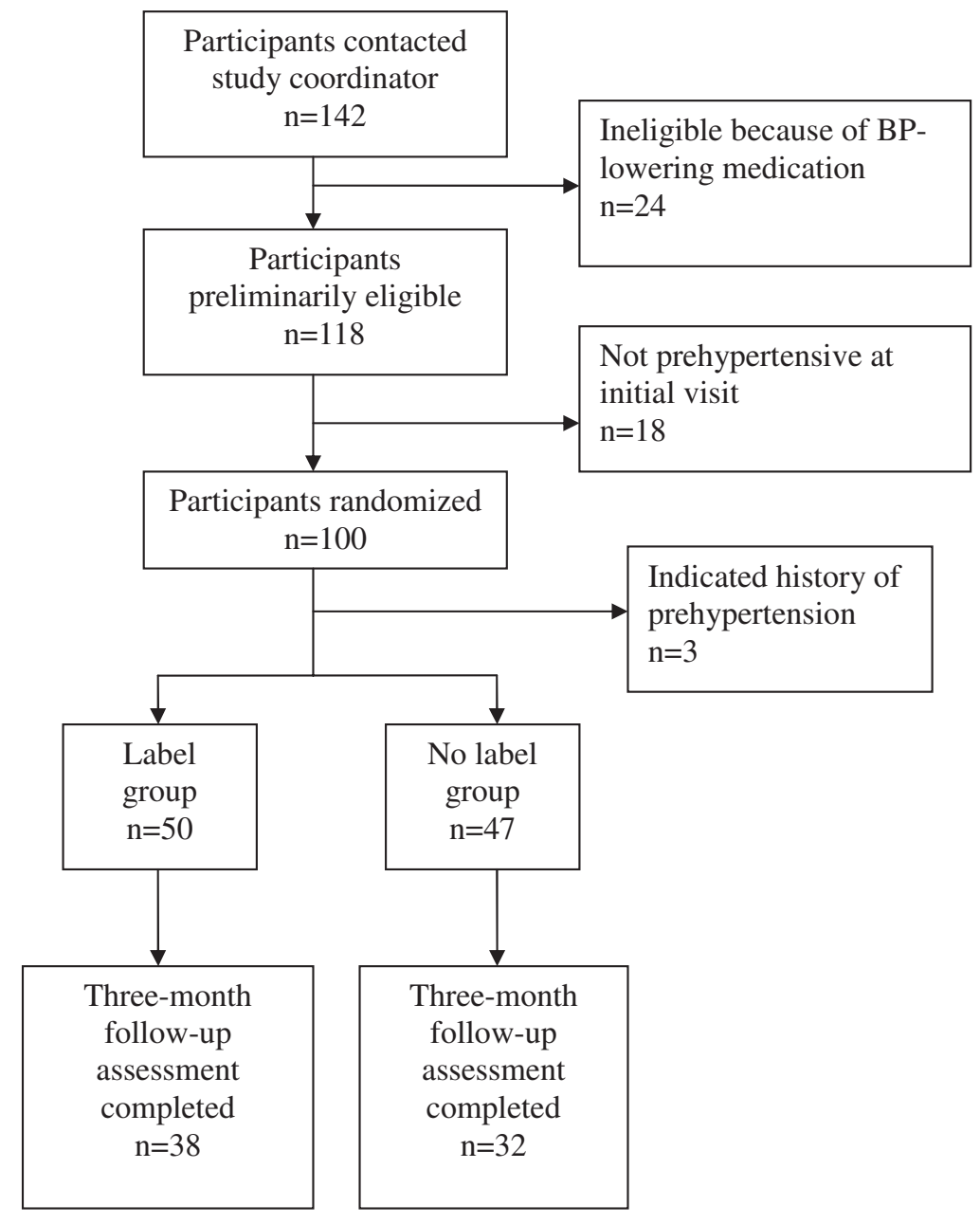

$72 \%$ (70 of 97). Differential loss to follow-up was $8 \%$, and nonrespondents were more likely to have less education, be of a race/ethnicity other than white, and be smokers (Table 2).

\section{Effects on Perceived Health}

At 3 months there was no significant difference between the 2 groups in change of self-reported health compared with baseline or in overall selfreported health status (Table 3). Among the label group, $58 \%$ indicated that their health at 3 months was the same; among the no label group, $56 \%$ indicated that their health status at 3 months was the same. Approximately $43 \%$ of respondents indicated that their health was either "much better" or "somewhat better" than at baseline, but the difference between the 3 groups was not significant. Only one respondent (in the no label group) indicated that his/her health was worse. There was no significant difference in the median overall selfreported health between the 2 groups.

\section{Effects on Lifestyle Modifications}

At 3 months there were no significant differences in the proportions of respondents who reported adopting recommended lifestyle modifications to prevent high BP (Table 4). The proportions of people who reported adopting the lifestyle modifications at 3 months were high (66\% for reducing alcohol, $84 \%$ for changing eating habits, $79 \%$ for exercising, and $90 \%$ for cutting down on salt), but there were no significant differences between the 2 groups. Risk ratios ranged from 0.99 to 1.23 , and 95\% CI limits ranged from 0.80 to 1.90 .

\section{Discussion}

The label of "prehypertension" seems to exert no negative effect on people's perception of their 
Table 1. Characteristics of Enrolled Participants

\begin{tabular}{|c|c|c|c|c|}
\hline & $\begin{array}{l}\text { Overall }(\mathrm{n}) \\
(\mathrm{n}=97)\end{array}$ & $\begin{array}{l}\text { No Label Group (n [\%]) } \\
\qquad(\mathrm{n}=47)\end{array}$ & $\begin{array}{l}\text { Label Group (n [\%]) } \\
\qquad(\mathrm{n}=50)\end{array}$ & $P$ \\
\hline Age category (years) & & & & .27 \\
\hline $24-39$ & 49 & $21(45)$ & $28(56)$ & \\
\hline$\geq 40$ & 48 & $26(55)$ & $22(44)$ & \\
\hline Female sex & 43 & $20(43)$ & $23(46)$ & .73 \\
\hline Race & & & & .26 \\
\hline White & 36 & $18(38)$ & $18(36)$ & \\
\hline Black & 49 & $22(47)$ & $27(54)$ & \\
\hline Other & 12 & $7(16)$ & $5(10)$ & \\
\hline Hispanic ethnicity & 10 & $7(15)$ & $3(6)$ & .15 \\
\hline Education level & & & & .42 \\
\hline$<$ High school & 11 & $7(15)$ & $4(8)$ & \\
\hline High school graduate & 9 & $6(13)$ & $3(6)$ & \\
\hline Some college & 33 & $15(32)$ & $18(36)$ & \\
\hline College graduate & 44 & $19(40)$ & $25(50)$ & \\
\hline Self-reported health & & & & .19 \\
\hline Excellent & 19 & $5(11)$ & $14(28)$ & \\
\hline Very good & 41 & $23(49)$ & $18(36)$ & \\
\hline Good & 33 & $17(36)$ & $16(32)$ & \\
\hline Fair & 4 & $2(4)$ & $2(4)$ & \\
\hline Poor & 0 & 0 & 0 & \\
\hline Married or living with partner & 48 & $24(51)$ & $24(48)$ & .84 \\
\hline Current smoker & 28 & $13(28)$ & $15(30)$ & .80 \\
\hline \multicolumn{5}{|l|}{ Medical problems* } \\
\hline Anxiety & 9 & $7(15)$ & $2(4)$ & .09 \\
\hline Asthma & 8 & $1(2)$ & $7(14)$ & .06 \\
\hline Arthritis or chronic pain & 9 & $5(11)$ & $4(8)$ & .74 \\
\hline Cancer & 1 & $1(2)$ & $0(0)$ & .49 \\
\hline Depression & 16 & $8(17)$ & $8(16)$ & 1.0 \\
\hline Heartburn & 7 & $2(4)$ & $5(10)$ & .44 \\
\hline High cholesterol & 11 & $6(13)$ & $5(10)$ & .76 \\
\hline Migraines & 6 & $2(4)$ & $4(8)$ & .68 \\
\hline Thyroid disorder & 3 & $1(2)$ & $2(4)$ & 1.0 \\
\hline None of the above & 23 & $11(23)$ & $12(24)$ & 1.0 \\
\hline Average systolic BP (mm Hg) & 129.0 & 128.6 & 129.4 & $.57^{\dagger}$ \\
\hline Average diastolic BP (mm Hg) & 81.9 & 81.7 & 82.1 & $.75^{\dagger}$ \\
\hline
\end{tabular}

BP, blood pressure.

${ }^{*} P$ for differences in medical problems by Fisher's exact test; all others by $\chi^{2}$ test unless otherwise noted.

${ }^{\dagger} P$ calculated by $t$ test.

health. Although we did not explore absenteeism from work or other manifestations of adopting the "sick role," this finding is reassuring. That is, a label of prehypertension does not seem to be perceived as having the same connotations as a label of hypertension. However, we found that the label of "prehypertension" does not seem to help people either. That is, we found no evidence that it motivates people to adopt recommended lifestyle changes that help prevent hypertension. This finding is im- portant because it addresses the clinical utility of the category of prehypertension.

The proportion of patients seen in the primary care setting with $\mathrm{BP}$ in the prehypertensive range is substantial. ${ }^{20}$ For most patients with prehypertension, however, the absolute risk of cardiovascular disease events is not high enough to justify treatment with an antihypertensive medication. Therefore, counseling is the only other tool that clinicians have to try to address this problem. Unfortunately, 


\begin{tabular}{|c|c|c|c|}
\hline & Nonrespondents $(\mathrm{n}=27)$ & Respondents $(\mathrm{n}=70)$ & $P$ \\
\hline Age category (years) & & & .54 \\
\hline $24-39$ & $15(56)$ & $34(49)$ & \\
\hline$\geq 40$ & $12(44)$ & $36(51)$ & \\
\hline Female sex & $9(33)$ & $34(49)$ & .18 \\
\hline \multicolumn{4}{|l|}{ Race } \\
\hline White & $4(15)$ & $32(46)$ & .002 \\
\hline Black & $16(59)$ & $33(47)$ & \\
\hline Other & $7(26)$ & $3(4)$ & \\
\hline Hispanic ethnicity & $7(26)$ & $3(4)$ & .002 \\
\hline Education level & & & .03 \\
\hline$<$ High school & $7(26)$ & $4(6)$ & \\
\hline High school graduate & $3(11)$ & $6(9)$ & \\
\hline Some college & $9(33)$ & $24(34)$ & \\
\hline College graduate & $8(30)$ & $36(51)$ & \\
\hline Self-reported health & & & .46 \\
\hline Excellent & $3(11)$ & $16(23)$ & \\
\hline Very good & $11(41)$ & $30(43)$ & \\
\hline Good & $12(44)$ & $21(30)$ & \\
\hline Fair & $1(4)$ & $3(4)$ & \\
\hline Poor & 0 & 0 & \\
\hline Married or living with partner & $11(41)$ & $37(53)$ & .25 \\
\hline Current smoker & $14(52)$ & $14(20)$ & .002 \\
\hline \multicolumn{4}{|l|}{ Medical problems* } \\
\hline Anxiety & $2(7)$ & $7(10)$ & 1.0 \\
\hline Asthma & $2(7)$ & $6(9)$ & 1.0 \\
\hline Arthritis or chronic pain & $1(4)$ & $8(11)$ & .44 \\
\hline Cancer & 0 & $1(1)$ & 1.0 \\
\hline Depression & $5(19)$ & $11(16)$ & .77 \\
\hline Heartburn & $2(7)$ & $5(7)$ & 1.0 \\
\hline High cholesterol & $1(4)$ & $10(14)$ & .28 \\
\hline Migraines & 0 & $6(9)$ & .18 \\
\hline Thyroid disorder & 0 & $3(4)$ & .56 \\
\hline None of the above & $9(33)$ & $14(20)$ & .19 \\
\hline Average systolic BP (mm Hg) & 129.2 & 128.9 & $.84^{\dagger}$ \\
\hline Average diastolic BP (mm Hg) & 82.8 & 81.6 & $.36^{\dagger}$ \\
\hline
\end{tabular}

Values provided as $\mathrm{n}(\%)$. BP, blood pressure.

${ }^{*} P$ for differences in medical problems by Fisher's exact test; all others by $\chi^{2}$ test unless otherwise noted.

${ }^{\dagger} P$ calculated by $t$ test.

however, it seems that use of the term "prehypertension" does not enhance the effectiveness of counseling about measures that can be taken to prevent hypertension.

The most important lesson from this study may be that a clinical strategy currently plays a limited role in the prevention of hypertension. In the United States, a person's lifetime risk of hypertension is estimated to be $90 \% .{ }^{21}$ Therefore, in a very real sense, almost all Americans are prehypertensive. Population-level strategies (eg, sodium reduc- tion in the food and restaurant industry and efforts to combat obesity and physical inactivity) hold much more promise for preventing hypertension. $^{22-25}$

\section{Considerations}

In actual clinical practice, a health care provider rather than a research assistant would inform a patient about prehypertension and discuss the lifestyle recommendations. We chose to use a trained research assistant to deliver the messages so that 


\begin{tabular}{lccc}
\hline & All respondents $(\mathrm{n}=70)$ & No label group $(\mathrm{n}=32)$ & Label group $(\mathrm{n}=38)$ \\
\hline Compared to baseline & & & $P^{*}$ \\
Better & $29(41.4)$ & $13(40.6)$ & $16(42.1)$ \\
Same & $40(57.1)$ & $18(56.3)$ & $22(57.9)$ \\
Worse & $1(1.4)$ & $1(3.1)$ & 0 \\
Overall self-reported health & $14(20.0)$ & $4(12.5)$ & $10(26.3)$ \\
Excellent & $28(40.0)$ & $14(43.8)$ & $14(36.8)$ \\
Very good & $22(31.4)$ & $11(34.4)$ & $11(29.0)$ \\
Good & $6(8.6)$ & $3(9.4)$ & $3(7.9)$ \\
Fair & 0 & 0 & 0 \\
Poor & & & .30 \\
\hline
\end{tabular}

All values provided as $\mathrm{n}(\%)$.

*P calculated by Wilcoxon-Mann-Whitney test.

they could be standardized. Our aim in developing what we considered to be the "labeling" message was to try to present a balance of information that might actually occur in the clinical setting when a health care provider informs a patient that he or she has prehypertension. That is, after the diagnosis of prehypertension is discussed, its meaning for the patient and the management options would also be discussed. We assumed that such labeling could have positive effects, negative effects, both, or neither. Although a physician might tailor the message he or she presents to a specific patient, and a relationship between a patient and his/her personal physician might contribute to the effects of labeling (either positively or negatively), in our experimental design we tried to isolate as much as possible the actual effect of the label itself compared with a more general preventive message.

Our method of recruiting participants probably attracted people who are generally more interested in their health and in health promotion. However, most people who would be counseled about prehypertension would probably be told at a wellness or health maintenance visit when there is time to ex- plain it and the lifestyle recommendations designed to prevent or delay hypertension. People who make health maintenance visits are generally more interested in their health and in preventive care than those who do not make such visits. ${ }^{26}$ Therefore, we feel that the study population was representative of those who would be told about prehypertension in true patient care situations. Further, the goal of informing patients about prehypertension is to delay or prevent hypertension, which is what the recruitment title of the study reflected.

The potential for measurement bias must be considered and could arise for 3 main reasons. First, the questions we used to assess potential negative effects on perceived health may not have been sensitive enough, or 3 months may be too long a time to wait to detect negative perceptions. However, the necessity of either a more sensitive instrument or a more immediate assessment to detect potential psychological effects probably means that such effects are small or transient. Second, we recognize the self-reporting bias inherent in our outcome measure. However, this bias should be the same in both groups. Finally, a nonresponse bias

Table 4. Reported Health Behaviors at 3 Months

\begin{tabular}{|c|c|c|c|c|c|}
\hline & All Respondents (\%) & No Label Group (\%) & Label Group (\%) & Risk Ratio & $95 \% \mathrm{CI}$ \\
\hline Changing eating habits* & 83.8 & 81.3 & 86.1 & 1.06 & $0.86-1.31$ \\
\hline Cutting down on salt & 90.0 & 90.6 & 89.5 & 0.99 & $0.84-1.15$ \\
\hline Reducing alcohol intake $^{\dagger}$ & 65.9 & 59.1 & 72.7 & 1.23 & $0.80-1.90$ \\
\hline Exercising & 78.6 & 71.9 & 84.2 & 1.17 & $0.91-1.51$ \\
\hline
\end{tabular}

*Based on 68 respondents because 2 respondents indicated "not sure."

${ }^{\dagger}$ Among the 44 respondents who drank alcohol. 
may exist if those who are not white, those who had less education, or smokers would report changes in perceived health status or measures being taken to prevent hypertension differently than respondents.

\section{Conclusions}

Informing patients that they have prehypertension as part of a message designed to prevent hypertension does not seem to be harmful. However, it does not seem to be helpful, either. The clinical utility of "prehypertension" is questionable. The extent to which clinicians are motivated to counsel prehypertensive patients as part of a cardiovascular disease prevention strategy is unknown.

\section{References}

1. Haynes RB, Sackett DL, Taylor DW, et al. Increased absenteeism from work after detection and labeling of hypertensive patients. N Engl J Med 1978;299:741-4.

2. Polk BF, Harlan LC, Cooper SP, et al. Disability days associated with detection and treatment in a hypertension control program. Am J Epidemiol 1984;119:44-53.

3. Alderman MH, Charlson ME, Melcher LA. Labelling and absenteeism: the Massachusetts Mutual Experience. Clin Invest Med 1981;4:165-71.

4. Taylor DW, Haynes RB, Sackett DL, Gibson ES. Long-term follow-up of absenteeism among working men following the detection and treatment of their hypertension. Clin Invest Med 1981;4:173-7.

5. Monk M. Blood pressure awareness and psychological well-being in the health and nutrition examination survey. Clin Invest Med 1981;4:183-9.

6. Bloom JR, Monterossa S. Hypertension labeling and sense of well-being. Am J Pub Health 1981; 71:1228-32.

7. Barger SD, Muldoon MF. Hypertension labeling was associated with poorer self-rated health in the third US national health and nutrition examination survey. J Hum Hypertens 2006;20:117-23.

8. Francisco M, Martin-Escudero JC, Simal-Blanco F, et al. Health-related qualify of life of subjects with known and unknown hypertension: results from the population-based Hortega study. J Hypertens 2003; 21:1283-9.

9. Mold JW, Hamm RM, Jafri B. The effect of labeling on perceived ability to recover from acute illnesses and injuries. J Fam Pract 2000;49:437-40.

10. Chobanian AV, Bakris GL, Black HR, et al. The seventh report of the Joint National Committee on prevention, detection, evaluation, and treatment of high blood pressure: the JNC 7 report. JAMA 2003; 289:2560-72.

11. Wang Y, Wang QJ. The prevalence of prehyperten- sion and hypertension among US adults according to the new Joint National Committee guidelines. Arch Intern Med 2004;164:2126-34.

12. Svetkey LP. Management of prehypertension. Hypertension 2005;45:1056-61.

13. O'Brien E, Pickering T, Asmar R, et al. Working Group on Blood Pressure Monitoring of the European Society of Hypertension International Protocol for validation of blood pressure measuring devices in adults. Blood Press Monit 2002;7:3-17.

14. Brazier JE, Harper R, Jones NM, et al. Validating the SF-36 health survey questionnaire: new outcome measure for primary care. BMJ 1992;305:160-4.

15. National Heart Lung and Blood Institute. Your Guide to Lowering High Blood Pressure, NHLBI. Available at http://www.nhlbi.nih.gov/hbp/index. html. Accessed 29 July 2010.

16. Centers for Disease Control and Prevention. Behavioral Risk Factor Surveillance System Survey Questionnaire. Atlanta, GA: U.S. Department of Health and Human Services, Centers for Disease Control and Prevention; 2005.

17. Zhao YD, Rahardja D, Qu Y. Sample size calculation for the Wilcoxon-Mann-Whitney test adjusting for ties. Stat Med 2008;27:462-8.

18. Nanna MJ, Sawilowsky SS. Analysis of Likert scale data in disability and medical rehabilitation research. Psychol Methods 1998;3:55-67.

19. Campbell MJ, Julious SA, Altman DG. Estimating sample sizes for binary, ordered categorical, and continuous outcomes in two group comparisons. BMJ 1995;311:1145-8.

20. Viera AJ. The "new" normal blood pressure: what are the implications for family medicine? J Am Board Fam Med 2007;20:45-51.

21. Vasan RS, Beiser A, Seshadri S, et al. Residual lifetime risk for developing hypertension in middleaged women and men: the Framingham Heart Study. JAMA 2002;287:1003-10.

22. Whelton PK, He J, Appel LJ, et al. Primary prevention of hypertension: clinical and public health advisory from the National High Blood Pressure Education Program. JAMA 2002;288:1882-8.

23. Havas S, Dickinson BD, Wilson M. The urgent need to reduce sodium consumption. JAMA 2007;298: $1439-41$.

24. Zaman MJ. Health protection requires legislation. BMJ 2007;334:967.

25. Bibbins-Domingo K, Chertow GM, et al. Projected effect of dietary salt reductions on future cardiovascular disease. N Engl J Med 2010;362:590-9.

26. Cherrington A, Corbie-Smith G, Pathman DE. Do adults who believe in periodic health examinations receive more clinical preventive services? Prev Med 2007;45:282-9. 


\section{Appendix 1: Draft of "Label" Script}

Much of this has been adapted from information available on the website of the National Heart, Lung, and Blood Institute. ${ }^{15}$

\section{Message " $\mathrm{"}$}

The research assistant introduces him/her self and explains that he/she has been trained by the physician to deliver the following health messages.

Blood pressure is the force of blood against the walls of arteries. Your blood pressure rises and falls during the day. When blood pressure stays elevated over time, it is called "high blood pressure." The medical term for high blood pressure is "hypertension." High blood pressure is dangerous because it makes the heart work too hard and contributes to atherosclerosis, also known as "hardening of the arteries." It increases the risk of heart disease and stroke, which are the first- and third-leading causes of death among Americans. High blood pressure also can result in other conditions, such as congestive heart failure, kidney disease, and blindness.

A blood pressure level of 140/90 mm $\mathrm{Hg}$ or higher is considered high. People with blood pressure in this range have hypertension. A normal blood pressure is considered $<120 / 80 \mathrm{~mm} \mathrm{Hg}$. Based on your blood pressure readings, you have what doctors call "prehypertension." This means that you don't have high blood pressure now but are likely to develop it in the future.

You can take steps to treat your prebypertension and prevent high blood pressure by adopting a healthy lifestyle. These steps include maintaining a healthy weight; being physically active; following a healthy eating plan that emphasizes fruits, vegetables, and low-fat dairy foods; choosing and preparing foods with less salt and sodium; and, if you drink alcoholic beverages, drinking in moderation. I am going to talk a little bit more about each of these.

Following a healthy eating plan can reduce your risk of developing high blood pressure from your prebypertension. For an overall eating plan, you should consider the DASH eating plan. DASH stands for Dietary Approaches to Stop Hypertension, a clinical study that tested the effects of nutrients in food on blood pressure. Study results indicated that blood pressures were reduced by an eating plan that emphasizes fruits, vegetables, and low-fat dairy foods and is low in saturated fat, total fat, and cholesterol. The DASH eating plan includes whole grains, poultry, fish, and nuts and has lower amounts of fats, red meats, sweets, and sugared beverages.

A second clinical study, called "DASH-Sodium," looked at the effect of a reduced dietary sodium intake on blood pressure as people followed either the DASH eating plan or a typical American diet. Sodium is what is found in common "table salt" and in many processed and canned foods. Results showed that reducing dietary sodium lowered blood pressure among people on both the DASH eating plan and the typical American diet. The biggest blood pressure-lowering benefits were for those eating the DASH eating plan at the lowest sodium level. In that study, those individuals had less than $1,500 \mathrm{mg}$ of sodium per day. A key to healthy eating is choosing foods lower in salt and sodium. Most Americans consume more salt than they need. The current recommendation is to consume less than 2.4 grams (2,400 milligrams) of sodium a day. That equals 6 grams (about 1 teaspoon) of table salt a day. The 6 grams include all salt and sodium consumed, including that used in cooking and at the table.

Fats-especially saturated fat-affect the health of your heart and blood vessels. There are various types of fat. Saturated fat is often found in foods from animals. This includes fatty meats, the skin of poultry, and whole-milk dairy products, such as butter, cheese, cream, and ice cream. It also is in coconut, palm kernel, and palm oils. These oils are found mostly in processed foods, such as baked goods, snack foods, and crackers. If you use saturated fat, keep the amount small. Instead of saturated fat, try soft or liquid margarine and such oils as canola, safflower, and olive. However, all kinds of fats have the same amount of calories and need to be limited to help you lose weight.

At this point the research assistant goes over the following information, adapted from the National Heart, Lung, and Blood Institute website. ${ }^{15}$ These could be formatted into handouts to be provided to patients.

\section{Getting Started with DASH}

It's easy to adopt the DASH eating plan. Here are some ways to get started:

Change gradually. 
- If you now eat one or two vegetables a day, add a serving at lunch and another at dinner.

- If you don't eat fruit now or have only juice at breakfast, add a serving to your meals or have it as a snack.

- Use only half the butter, margarine, or salad dressing you do now.

- Try low-fat or fat-free condiments, such as fatfree salad dressings.

- Gradually increase dairy products to 3 servings per day. For example, drink milk with lunch or dinner instead of soda, alcohol, or sugar-sweetened tea. Choose low-fat (1\%) or fat-free (skim) dairy products to reduce total fat intake.

Treat meat as one part of the whole meal, instead of the focus.

- Buy less meat. If it's not there, you won't eat it.

- Limit meat to $6 \mathrm{oz}$ a day (2 servings) - all that's needed. Three to $4 \mathrm{oz}$ is about the size of a deck of cards.

- If you now eat large portions of meat, cut them back gradually, by a half or a third at each meal.

- Include 2 or more vegetarian-style (meatless) meals each week.

- Increase servings of vegetables, rice, pasta, and dry beans in meals. Try casseroles, pasta, and stir-fry dishes, which have less meat and more vegetables, grains, and dry beans.

Use fruits or low-fat foods as desserts and snacks.

- Fruits and low-fat foods offer great taste and variety. Use fruits canned in their own juice. Fresh fruits require little or no preparation. Dried fruits are easy to carry with you.

- Try these snack ideas: unsalted pretzels or nuts mixed with raisins; graham crackers; low-fat and fat-free yogurt and frozen yogurt; plain popcorn with no salt or butter added; and raw vegetables.

\section{Tips for Reducing Sodium in Your Diet}

- Buy fresh, plain frozen, or canned "with no salt added" vegetables.

- Use fresh poultry, fish, and lean meat rather than canned or processed types.

- Use herbs, spices, and salt-free seasoning blends in cooking and at the table.
- Cook rice, pasta, and hot cereals without salt. Cut back on instant or flavored rice, pasta, and cereal mixes, which usually have added salt.

- Choose "convenience" foods that are lower in sodium. Cut back on frozen dinners, pizza, packaged mixes, canned soups or broths, and salad dressings - these often contain a lot of sodium.

- Rinse canned foods, such as tune, to remove some sodium.

- When available, buy low- or reduced-sodium or no-salt-added versions of foods.

- Choose ready-to-eat breakfast cereals that are lower in sodium.

\section{Continuing the Discussion}

Let's continue our discussion of things you can do to treat your prehypertension and try to prevent high blood pressure.

Being overweight increases your risk of developing high blood pressure. In fact, blood pressure rises as body weight increases. Losing even 10 pounds can lower blood pressure.

Being physically active is one of the most important steps you can do to belp control prebypertension. Exercise also helps reduce your risk of heart disease. It doesn't take a lot of effort to become physically active. You can get started by doing 30 minutes of a moderate-level activity on most-and preferably all-days of the week. Brisk walking, bicycling, and gardening are examples. You can even divide the 30 minutes into shorter periods of at least 10 minutes each.

If you already engage in 30 minutes of moderate-level physical activity a day, you can get added benefits by doing more. Engage a moderate-level activity for a longer period each day or engage in a more vigorous activity.

I just have a couple more things to tell you about.

Drinking too much alcohol can raise blood pressure. It also can harm the liver, brain, and heart. Alcoholic drinks also contain calories, which matter if you are trying to lose weight. If you drink alcoholic beverages, have only a moderate amountone drink a day for women; 2 drinks a day for men. You may be wondering: What counts as a drink?

- $12 \mathrm{oz}$ of beer (regular or light, 150 calories), or

- 5 oz of wine (100 calories), or

- $1 \frac{1}{2}$ oz of 80 -proof whiskey (100 calories). 
One last thing. We know that smoking injures blood vessel walls and speeds up the process of hardening of the arteries. This even applies to filtered cigarettes. So even though it does not cause high blood pressure, smoking is bad for anyone, especially those who have high blood pressure. So, if you smoke, quit. Once you quit, your risk of having a heart attack is reduced after the first year. If you don't smoke, don't start.

So, in summary, you have prebypertension, but there are things you can do to try to prevent the development of hypertension. You should adopt the DASH eating plan, increase your physical activity, cut down on the sodium in your diet, and lose weight, especially if you are overweight now. Finally, if you drink more alcohol than what we talked about, you should cut down, and if you smoke, you should quit.

Do you have any questions I can try to answer for you at this time? Thank you again for participating in our study. Be on the lookout for a questionnaire to be arriving in your mailbox in about 3 months, and be sure to fill it out and mail it back to us!

\section{Appendix 2: Draft of "No-Label" Script}

Much of this has been adapted from information available on the website of the National Heart Lung and Blood Institute. ${ }^{15}$

\section{Message " $N$ "}

A research assistant introduces him/her self and explains that he/she has been trained by physician to deliver the following health messages.

Blood pressure is the force of blood against the walls of arteries. Your blood pressure rises and falls during the day. When blood pressure stays elevated over time, it is called "high blood pressure." The medical term for high blood pressure is "hypertension." High blood pressure is dangerous because it makes the heart work too hard and contributes to atherosclerosis, also known as "hardening of the arteries." It increases the risk of heart disease and stroke, which are the first- and third-leading causes of death among Americans. High blood pressure also can result in other conditions, such as congestive heart failure, kidney disease, and blindness.

A blood pressure level of 140/90 $\mathrm{mm} \mathrm{Hg}$ or higher is considered high. People with blood pressure in this range have hypertension. Hypertension is a very common risk factor for heart disease and stroke. Many people develop hypertension and are prescribed medications to reduce their risk of heart disease and stroke.

You can take steps now to try to prevent high blood pressure by adopting a healthy lifestyle. These steps include maintaining a healthy weight; being physically active; following a healthy eating plan that emphasizes fruits, vegetables, and low-fat dairy foods; choosing and preparing foods with less salt and sodium; and, if you drink alcoholic beverages, drinking in moderation. I am going to talk a little bit more about each of these.

Following a healthy eating plan can reduce your risk of developing high blood pressure. For an overall eating plan, you should consider the DASH eating plan. DASH stands for Dietary Approaches to Stop Hypertension, a clinical study that tested the effects of nutrients in food on blood pressure. Study results indicated that blood pressure was reduced by following an eating plan that emphasizes fruits, vegetables, and low-fat dairy foods and is low in saturated fat, total fat, and cholesterol. The DASH eating plan includes whole grains, poultry, fish, and nuts and has lower amounts of fats, red meats, sweets, and sugared beverages.

A second clinical study, called DASH-Sodium, looked at the effect of a reduced dietary sodium intake on blood pressure as people followed either the DASH eating plan or a typical American diet. Sodium is what is found in common "table salt" and in many processed and canned foods. Results showed that reducing dietary sodium lowered blood pressure for both the DASH eating plan and the typical American diet. The biggest blood pressure-lowering benefits were for those who followed the DASH eating plan at the lowest sodium level. In that study, those individuals had less than 1,500 $\mathrm{mg}$ of sodium per day. A key to healthy eating is choosing foods that are lower in salt and sodium. Most Americans consume more salt than they need. The current recommendation is to consume less than 2.4 grams (2,400 milligrams) of sodium a day. That equals 6 grams (about 1 teaspoon) of table salt a day. The 6 grams include all salt and sodium consumed, including that used in cooking and at the table.

Fats-especially saturated fat-affect the health of your heart and blood vessels. There are various types of fat. Saturated fat is often found in foods from animals. This includes fatty meats, the skin of 
poultry, and whole-milk dairy products such as butter, cheese, cream, and ice cream. It also is in coconut, palm kernel, and palm oils. These oils are found mostly in processed foods, such as baked goods, snack foods, and crackers. If you use saturated fat, keep the amount small. Instead of saturated fat, try soft or liquid margarine and such oils as canola, safflower, and olive. However, all kinds of fats have the same amount of calories and need to be limited to help you lose weight.

At this point the research assistant goes over the following information, adapted from the National Heart, Lung, and Blood Institute website. ${ }^{15}$ These could be formatted into handouts to be provided to patients.

\section{Getting Started with DASH}

It's easy to adopt the DASH eating plan. Here are some ways to get started:

Change gradually.

- If you now eat one or two vegetables a day, add a serving at lunch and another at dinner.

- If you don't eat fruit now or have only juice at breakfast, add a serving to your meals or have it as a snack.

- Use only half the butter, margarine, or salad dressing you do now.

- Try low-fat or fat-free condiments, such as fatfree salad dressings.

- Gradually increase dairy products to 3 servings per day. For example, drink milk with lunch or dinner instead of soda, alcohol, or sugar-sweetened tea. Choose low-fat (1\%) or fat-free (skim) dairy products to reduce total fat intake.

Treat meat as one part of the whole meal, instead of the focus.

- Buy less meat. If it's not there, you won't eat it.

- Limit meat to $6 \mathrm{oz}$ a day (2 servings) —all that's needed. Three to $4 \mathrm{oz}$ is about the size of a deck of cards.

- If you now eat large portions of meat, cut them back gradually, by a half or a third at each meal.

- Include 2 or more vegetarian-style (meatless) meals each week.

- Increase servings of vegetables, rice, pasta, and dry beans in meals. Try casseroles, pasta, and stir-fry dishes, which have less meat and more vegetables, grains, and dry beans.
Use fruits or low-fat foods as desserts and snacks.

- Fruits and low-fat foods offer great taste and variety. Use fruits canned in their own juice. Fresh fruits require little or no preparation. Dried fruits are easy to carry with you.

- Try these snack ideas: unsalted pretzels or nuts mixed with raisins; graham crackers; low-fat and fat-free yogurt and frozen yogurt; plain popcorn with no salt or butter added; and raw vegetables.

\section{Tips for Reducing Sodium in Your Diet}

- Buy fresh, plain frozen, or canned "with no salt added" vegetables.

- Use fresh poultry, fish, and lean meat rather than canned or processed types.

- Use herbs, spices, and salt-free seasoning blends in cooking and at the table.

- Cook rice, pasta, and hot cereals without salt. Cut back on instant or flavored rice, pasta, and cereal mixes, which usually have added salt.

- Choose "convenience" foods that are lower in sodium. Cut back on frozen dinners, pizza, packaged mixes, canned soups or broths, and salad dressings-these often contain a lot of sodium.

- Rinse canned foods, such as tune, to remove some sodium.

- When available, buy low- or reduced-sodium or no-salt-added versions of foods.

- Choose ready-to-eat breakfast cereals that are lower in sodium.

\section{Continuing the Discussion}

Let's continue our discussion of things you can do try to prevent high blood pressure.

Being overweight increases your risk of developing high blood pressure. In fact, blood pressure rises as body weight increases. Losing even 10 pounds can lower blood pressure.

Being physically active is one of the most important steps you can do to try to prevent bypertension. Exercise also helps reduce your risk of heart disease. It doesn't take a lot of effort to become physically active. You can get started by doing 30 minutes of a moderate-level activity on most-and preferably all-days of the week. Brisk walking, bicycling, and gardening are examples. You can even divide the 30 minutes into shorter periods of at least 10 minutes each. 
If you already engage in 30 minutes of moderate-level physical activity a day, you can get added benefits by doing more. Engage a moderate-level activity for a longer period each day or engage in a more vigorous activity.

I just have a couple more things to tell you about.

Drinking too much alcohol can raise blood pressure. It also can harm the liver, brain, and heart. Alcoholic drinks also contain calories, which matter if you are trying to lose weight. If you drink alcoholic beverages, have only a moderate amountone drink a day for women; 2 drinks a day for men. You may be wondering: What counts as a drink?

- $12 \mathrm{oz}$ of beer (regular or light, 150 calories), or

- $5 \mathrm{oz}$ of wine (100 calories), or

- $1 \frac{1}{2}$ oz of 80 -proof whiskey (100 calories).

One last thing. We know that smoking injures blood vessel walls and speeds up the process of hardening of the arteries. This even applies to filtered cigarettes. So even though it does not cause high blood pressure, smoking is bad for anyone, especially those who have high blood pressure. So, if you smoke, quit. Once you quit, your risk of having a heart attack is reduced after the first year. If you don't smoke, don't start.

So, in summary, there are things you can do to try to prevent the development of hypertension. You should adopt the DASH eating plan, increase your physical activity, cut down on the sodium in your diet, and lose weight, especially if you are overweight now. Finally, if you drink more alcohol than what we talked about, you should cut down, and if you smoke, you should quit.

Do you have any questions I can try to answer for you at this time? Thank you again for participating in our study. Be on the lookout for a questionnaire to be arriving in your mailbox in about 3 months, and be sure to fill it out and mail it back to us!

\section{Appendix 3. Sample Size Calculations}

\begin{tabular}{|c|c|c|c|c|c|c|c|c|c|}
\hline \multirow[b]{2}{*}{ Scenario } & \multirow[b]{2}{*}{ Group } & \multicolumn{5}{|c|}{ Proportions } & \multirow[b]{2}{*}{$\pi^{*}$} & \multirow[b]{2}{*}{$\mathrm{n}$} & \multirow[b]{2}{*}{$\mathrm{n}_{1}=\mathrm{n}_{2}$} \\
\hline & & $\begin{array}{l}\text { Much } \\
\text { Worse }\end{array}$ & $\begin{array}{c}\text { Somewhat } \\
\text { Worse }\end{array}$ & $\begin{array}{l}\text { About } \\
\text { the Same }\end{array}$ & $\begin{array}{c}\text { Somewhat } \\
\text { Better }\end{array}$ & $\begin{array}{l}\text { Much } \\
\text { Better }\end{array}$ & & & \\
\hline \multirow[t]{2}{*}{1} & No Label & 0 & 0 & 0.7 & 0.25 & 0.05 & 0.67 & 58 & 29 \\
\hline & Label & 0.1 & 0.1 & 0.7 & 0.1 & 0 & & & \\
\hline \multirow[t]{2}{*}{2} & No Label & 0 & 0.05 & 0.8 & 0.1 & 0.05 & 0.66 & 56 & 28 \\
\hline & Label & 0.1 & 0.15 & 0.7 & 0.05 & 0 & & & \\
\hline \multirow[t]{2}{*}{3} & No Label & 0 & 0 & 0.9 & 0.1 & 0 & 0.64 & 52 & 26 \\
\hline & Label & 0.1 & 0.1 & 0.8 & 0 & 0 & & & \\
\hline
\end{tabular}

${ }^{*} \operatorname{Pr}($ no label $>$ label $)+0.5 \times \operatorname{Pr}($ no label $=$ label $)=$ competing probability that a nonlabeled individual has a better outcome than a labeled individual. 